Article

\title{
Synthesis, Characterization, and the Antioxidant Activity of Double Quaternized Chitosan Derivatives
}

\author{
Lijie Wei ${ }^{1,2}$, Qing Li ${ }^{1, *}$, Wenqiang Tan ${ }^{1,2}$, Fang Dong ${ }^{1}$, Fang Luan ${ }^{1,2}$ and Zhanyong Guo ${ }^{1,2, *}$ \\ 1 Key Laboratory of Coastal Biology and Bioresource Utilization, Yantai Institute of Coastal Zone Research, \\ Chinese Academy of Sciences, Yantai 264003, China; ljwei@yic.ac.cn (L.W.); wqtan@yic.ac.cn (W.T.); \\ fdong@yic.ac.cn (F.D.); fluan@yic.ac.cn (F.L.) \\ 2 University of Chinese Academy of Sciences, Beijing 100049, China \\ * Correspondence: qli@yic.ac.cn (Q.L.); zhanyongguo@hotmail.com (Z.G.); \\ Tel.: +86-535-210-9165 (Q.L.); +86-535-210-9171 (Z.G.)
}

Academic Editors: Luciano Saso, László Dux, Grzegorz Wegrzyn and Tamás Csont Received: 19 January 2017; Accepted: 17 March 2017; Published: 22 March 2017

\begin{abstract}
With the specialty of improving the water solubility of chitosan, quaternary ammonium salts have broadened the application of this polysaccharide in food, medicine and pesticides. To identify the effect of quaternary ammonium salts' quantity, single quaternized chitosan $N$-phenmethyl$\mathrm{N}, \mathrm{N}$-dimethyl chitosan (PDCS), double quaternized chitosan $\mathrm{N}$-(1-pyridylmethyl-2-ylmethyl)- $\mathrm{N}, \mathrm{N}$ dimethyl chitosan (MP2MDCS), $N$-(1-pyridylmethyl-3-ylmethyl)- $N, N$-dimethyl chitosan (MP3MDCS), and $N$-(1-pyridylmethyl-4-ylmethyl)- $N, N$-dimethyl chitosan (MP4MDCS) were designed and synthesized successfully through chemical modification of chitosan. Besides, three kinds of antioxidant activities, including hydroxyl radicals, superoxide radicals, and 1,1-Diphenyl-2-picrylhydrazyl (DPPH) radicals were tested in vitro. As shown in this paper, the scavenging ability was ranking in order of MP3MDC $>$ MP4MDCS $>$ MP2MDCS $>$ PDCS $>$ chitosan at $1.6 \mathrm{mg} / \mathrm{mL}$ in all assays. All double quaternary ammonium salts were better than chitosan or the single quaternary ammonium salt. In addition, MP3MDCS could scavenge hydroxyl radicals totally at $1.6 \mathrm{mg} / \mathrm{mL}$. MP2MDCS and MP4MDCS with more than $90 \%$ scavenging indices both had great scavenging ability on hydroxyl radicals or DPPH radicals. Furthermore, these data demonstrated that the increasing number of the positive charge would improve the antioxidant property of chitosan derivatives, and the $\mathrm{N}$-pyridinium position would influence the scavenging radical ability.
\end{abstract}

Keywords: single quaternized chitosan; double quaternized chitosan; chemical modification; antioxidant activity

\section{Introduction}

Free radicals, especially oxygen free radicals in one's body, may damage the chemical structure of the organized cell and cause symptoms, such as ruptures of the main chain of the nucleic acid and protein peptide bond, membrane lipid peroxidation, enzyme inactivation, and cell apoptosis in certain pathological conditions [1-5]. Fortunately, free radicals can be removed by the antioxidant, where the composite agent plays an important role in cleaning while protecting body cells from damaging [6]. Meanwhile, it was reported that some polysaccharides with free hydroxyl and amino group have antioxidant ability, and the order of scavenging hydroxyl radicals ability is chitosan > hyaluronan > starch [7]. Chitosan and chitosan derivatives, in consequence, have attracted numerous attentions as the natural antioxidants with inestimable potentials [8].

Chitosan, the natural cationic amino polysaccharide copolymer of glucosamine and $\mathrm{N}$-acetylglucosamine, is usually obtained from the exoskeletons of the shellfish and the insects. As a natural renewable resource, chitosan has advantages in unique physicochemical characteristics 
and bioactivities expressed as its antifungal, antioxidant and antitumor properties [9-13]. Due to the high degree of polymerization, however, this polysaccharide is limited by its poor solubility above pH 6.5 [14,15]. Therefore, functional derivatives prepared by chemical modification, such as quaternization, carboxylation, phosphorylation and sulfation, are introduced to enhance chitosan's water solubility and bioactivity while sustaining its original biodegradability and biocompatibility [16-21]. Actually, with the fact that molecular structures determine the biological activities of polysaccharides, studies of the structure activity relationship of polysaccharides start to gain their popularity [22]. And, one branch of this promising research, the analysis of different molecular structure of quaternary ammonium salts and their antioxidant abilities are the main idea in following parts of this paper.

Pyridine was introduced into the polysaccharide backbone in this article, since pyridine was widely used in agrochemicals and pharmaceuticals with an aromatic heterocycle as an important solvent and reagent $[23,24]$. $N$-pyridylmethy chitosan was synthesized based on the reaction between the primary amino group of chitosan and aldehyde group of pyridine carboxaldehyde following by the reduction with sodium borohydride $[25,26]$. Besides, the pyridine was easily attacked by alkylating agents to obtain $N$-alkylpyridinium salt since its chemical property was similar to tertiary amine [24]. Besides, it was reported that pyridine chitosan derivatives could improve polysaccharide properties including solubility, physicochemical and biological properties, which could be applied in antimicrobial activity, sensor application, and biomedical application [27-29]. It was reported that pyridinium derivatives have been shown to be non-toxic for genen delivery in vitro [30]. Furthermore, $N$-pyridinium positions could influence the efficiency in mental adsorption, and gene carriers [30-32]. However, less attention has been paid to the influence of $N$-pyridinium position on the antioxidant activity. Therefore, double quaternary ammonium salts at different $N$-pyridinium position with a similar degree of substitution (DS) were investigated in this paper.

It was reported that quaternized chitosan derivatives had better antioxidant abilities than any of chitosan, Schiff bases of chitosan or $N$-substituted chitosan, and proposed that the antioxidant activity was affected by the positive charge of quaternized chitosan derivatives [33,34]. In that case, the density of positive charge could influence the efficiency of antioxidant activities. Therefore, in order to further study the influence of the positive charge and $N$-pyridinium position of quaternized chitosan derivatives on antioxidant activities, $N$-phenmethyl- $N, N$-dimethyl chitosan (PDCS), $N$-(1-pyridylmethyl-2-ylmethyl)-N,N-dimethyl chitosan (MP2MDCS), N-(1-pyridylmethyl-3-ylmethyl)$N, N$-dimethyl chitosan (MP3MDCS), and N-(1-pyridylmethyl-4-ylmethyl)- $N, N$-dimethyl chitosan (MP4MDCS) were synthesized successfully via $N$-pyridylmethyl chitosan in this paper, and the antioxidant activity was also investigated systematically by the assessment of hydroxyl radicals' scavenging activity, superoxide radicals' scavenging activity, and DPPH radicals' scavenging activity. In the meantime, FT-IR, ${ }^{1} \mathrm{H}-\mathrm{NMR}$, and the elemental analyses characterized the chemical structure of the chitosan derivatives.

\section{Results}

\subsection{Structure of the Chitosan Derivative}

The synthetic procedures of the quaternary ammonium salts chitosan are shown in Scheme 1. $N$-(2-pyridylmethy), N-(3-pyridylmethy), and N-(4-pyridylmethy) chitosan were synthesized based on the reaction between the primary amino group of chitosan and aldehyde group of pyridine carboxaldehyde following by the reduction with sodium borohydride. Then, the secondary amine and $N$-pyridine were attacked by iodomethane to obtain quaternary ammonium salts, respectively. 


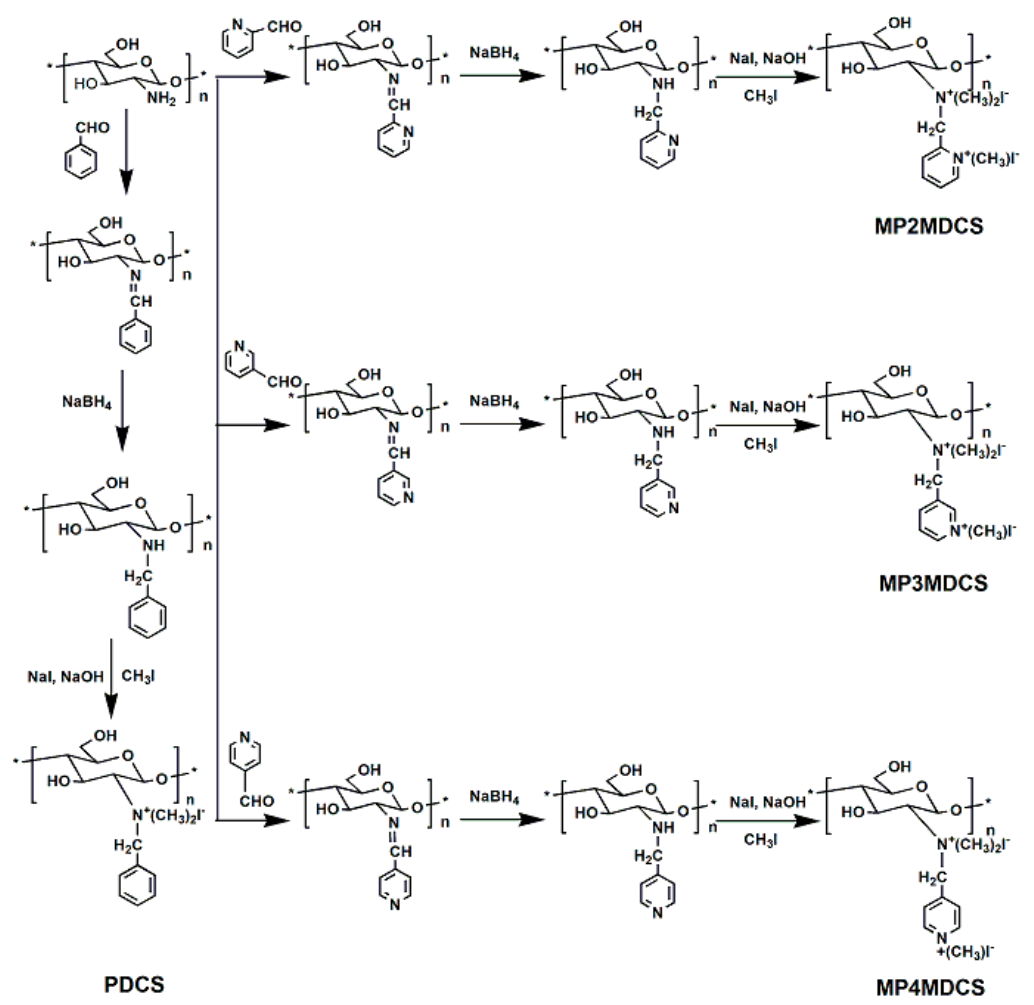

Scheme 1. Synthetic pathway of PDCS, MP2MDCS, MP3MDCS, and MP4MDCS.

The FT-IR spectrum data of chitosan, PDCS, MP2MDCS, MP3MDCS, and MP4MDCS were shown in Figure 1. The spectrum of chitosan showed that saccharide mainly contained the following characteristic bands: $v(\mathrm{O}-\mathrm{H})$ or $v(\mathrm{~N}-\mathrm{H}) 3428.81 \mathrm{~cm}^{-1}, v(\mathrm{C}-\mathrm{H}) 2919.70 \mathrm{~cm}^{-1}, v(\mathrm{O}=\mathrm{C}-\mathrm{NH}$ I band $)$ $1643.05 \mathrm{~cm}^{-1}, \delta(\mathrm{C}-\mathrm{H}) 1427.07,1380.78 \mathrm{~cm}^{-1}, v\left(\mathrm{O}=\mathrm{C}-\mathrm{NH}\right.$ III band) 1322.93 or $1261.22 \mathrm{~cm}^{-1}, v(\mathrm{C}-\mathrm{O})$ $1068.37 \mathrm{~cm}^{-1}$, and $898.67 \mathrm{~cm}^{-1}$ indicated the $\beta$ glycosidic bond. After quaternized, a new peak appeared at about $1546.63 \mathrm{~cm}^{-1}$ for PDCS, which was assigned to the benzene ring, and the peak at about $1461.78 \mathrm{~cm}^{-1}$ was the characteristic absorption of $\mathrm{N}-\mathrm{CH}_{3}$ [35]. The peaks of quaternary ammonium salts of MP2MDCS, MP3MDCS, and MP4MDCS appeared at $1515.78 \mathrm{~cm}^{-1}, 1515.78 \mathrm{~cm}^{-1}$, and $1546.63 \mathrm{~cm}^{-1}$, respectively. The absorption of $\mathrm{N}-\mathrm{CH}_{3}$ was at about $1461.78 \mathrm{~cm}^{-1}, 1465.64 \mathrm{~cm}^{-1}$, and $1469.49 \mathrm{~cm}^{-1}$ for MP2MDCS, MP3MDCS, and MP4MDCS, respectively. Moreover, double quaternized chitosan MP2MDCS, MP3MDCS, and MP4MDCS had new peaks at $779.10 \mathrm{~cm}^{-1}, 806.10 \mathrm{~cm}^{-1}$, and $813.81 \mathrm{~cm}^{-1}$, respectively, corresponding to the pyridine groups with different substitution position. Above results demonstrated preliminarily that quaternized chitosan derivatives were obtained.

Figure 2 showed the ${ }^{1} \mathrm{H}-\mathrm{NMR}$ spectra of PDCS, MP2MDCS, MP3MDCS, and MP4MDCS, respectively. It was known that all of the signals at 5.12 to $3.81 \mathrm{ppm}$ were assigned to the protons of glucose skeleton of chitosan. It exhibited characteristic resonance of $\mathrm{N}-\mathrm{CH}_{3}$ at about $3.35 \mathrm{ppm}$ for $\mathrm{C} 7$ in the molecules of PDCS, MP2MDCS, MP3MDCS, and MP4MDCS, respectively. At the same time, the peaks at $4.42,4.38$, and $4.39 \mathrm{ppm}$ should correspond to methyl protons grafted to pyridine for MP2MDCS, MP3MDCS, and MP4MDCS, respectively. And 8.0-9.3 ppm should correspond to the pyridine ring with different substitution position. The signal at $7.5 \mathrm{ppm}$ was assigned to the benzene ring. The above mentioned results demonstrated further that PDCS, MP2MDCS, MP3MDCS and MP4MDCS were obtained successfully. 


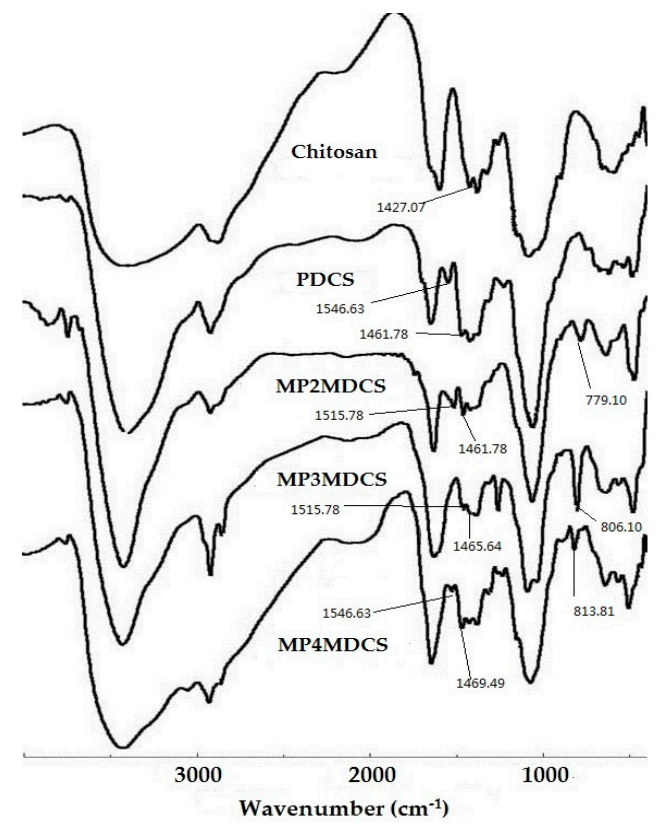

Figure 1. FT-IR spectra of Chitosan, PDCS, MP2MDCS, MP3MDCS, and MP4MDCS.

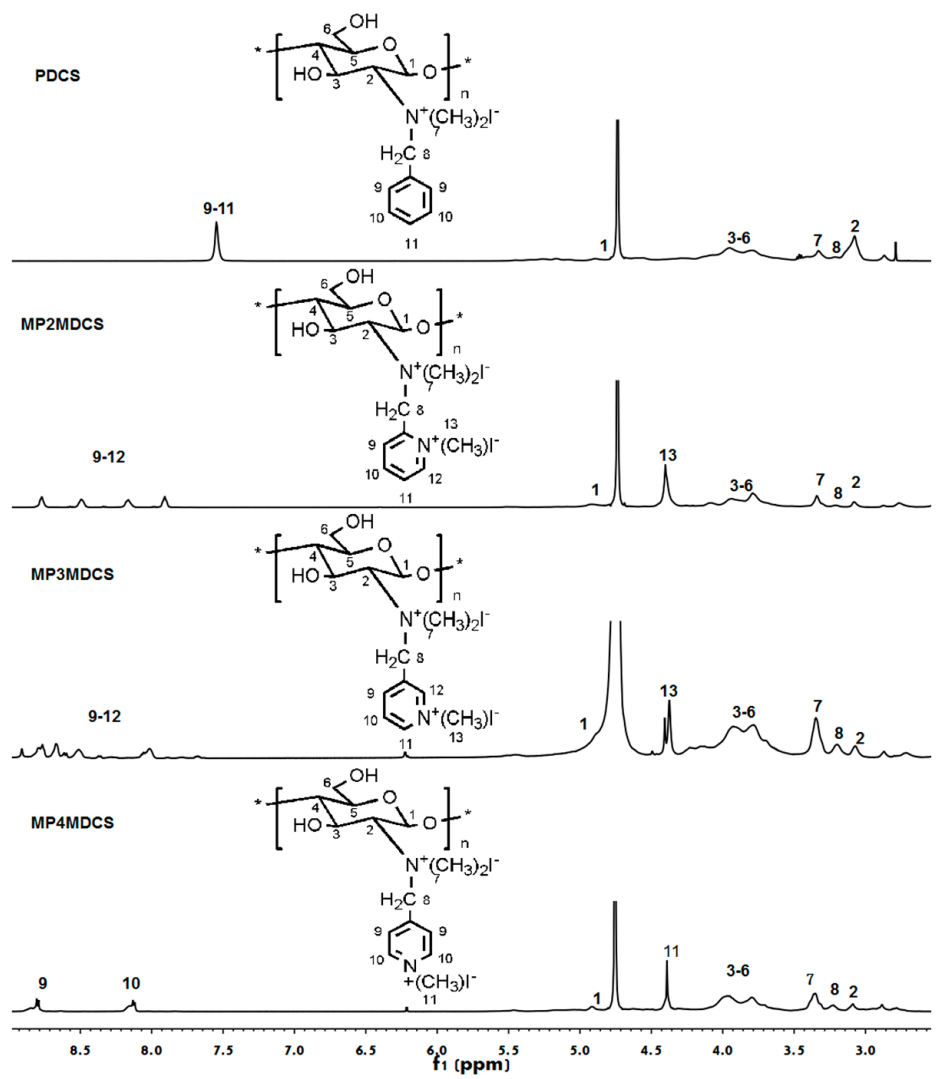

Figure 2. ${ }^{1} \mathrm{H}-\mathrm{NMR}$ spectra of PDCS, MP2MDCS, MP3MDCS, and MP4MDCS.

\subsection{Antioxidant Activity}

Chitosan has poor solubility in neutral water due to the high polymerization degree. We used the water-soluble chitosan with low molecular weight in all antioxidant activity tests. All quaternized chitosan derivatives had good solubility in water, and were prepared as aqueous solutions at the concentration of 0.1 to $1.6 \mathrm{mg} / \mathrm{mL}$. 
Figure 3 showed the superoxide radicals' scavenging ability of chitosan and all quaternized chitosan derivatives composed at 0.1 to $1.6 \mathrm{mg} / \mathrm{mL}$. According to the graph, we concluded the results as follows: Firstly, the superoxide radicals' scavenging ability of all samples enhanced with the increasing concentration. Secondly, scavenging indices were listed as follows at the concentration of $1.6 \mathrm{mg} / \mathrm{mL}$ : chitosan 40.75\%, PDCS 43.04\%, MP2MDCS 67.98\%, MP3MDCS 82.53\%, and MP4MDCS $76.80 \%$. These data showed that MP2MDCS, MP3MDCS and MP4MDCS had better superoxide radicals' scavenging ability than chitosan and PDCS at $1.6 \mathrm{mg} / \mathrm{mL}$. And all double quaternized chitosan derivatives had higher density of positive charges than chitosan and PDCS, which might conclude that the higher density of positive charges could contribute to the scavenging on the superoxide radicals' activity. Thirdly, in the three double quaternized chitosan derivatives, the scavenging properties of MP2MDCS, MP3MDCS, and MP4MDCS were similar at the lower concentration, but MP3MDCS gave much stronger scavenging ability at $1.6 \mathrm{mg} / \mathrm{mL}$, which might conclude that the different position of $N$-pyridinium might have some influence on the scavenging activity.

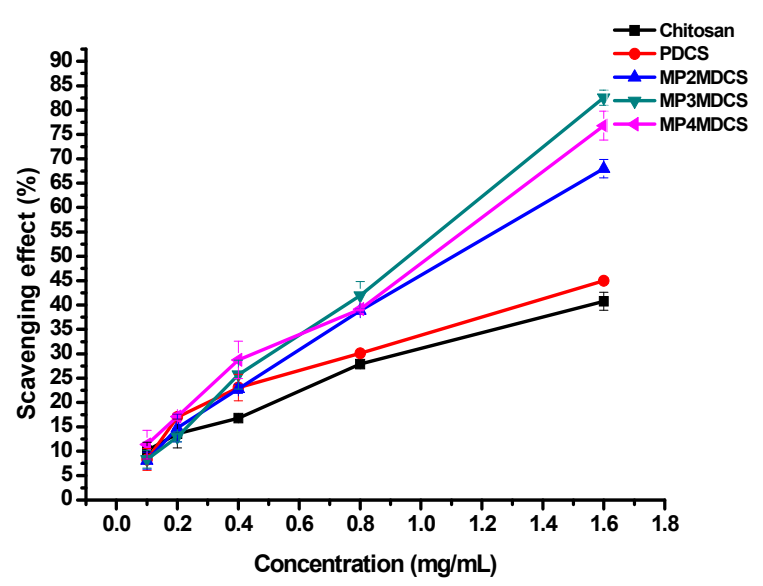

Figure 3. Superoxide radicals' scavenging ability of Chitosan, PDCS, MP2MDCS, MP3MDCS and MP4MDCS.

Figure 4 showed the curve chart of the hydroxyl radicals' scavenging ability of chitosan and the synthesized quaternized chitosan derivatives composed at 0.1 to $1.6 \mathrm{mg} / \mathrm{mL}$. The results were similar to above results on the superoxide radicals' scavenging activity. Firstly, the scavenging indices enhanced with the increasing concentration. Secondly, the scavenging ability against hydroxyl radicals was in order of MP3MDCS > MP4MDCS > MP2MDCS > PDCS > chitosan at the $1.6 \mathrm{mg} / \mathrm{mL}$. Thirdly, MP3MDCS could scavenge hydroxyl radicals totally at $1.6 \mathrm{mg} / \mathrm{mL}$.

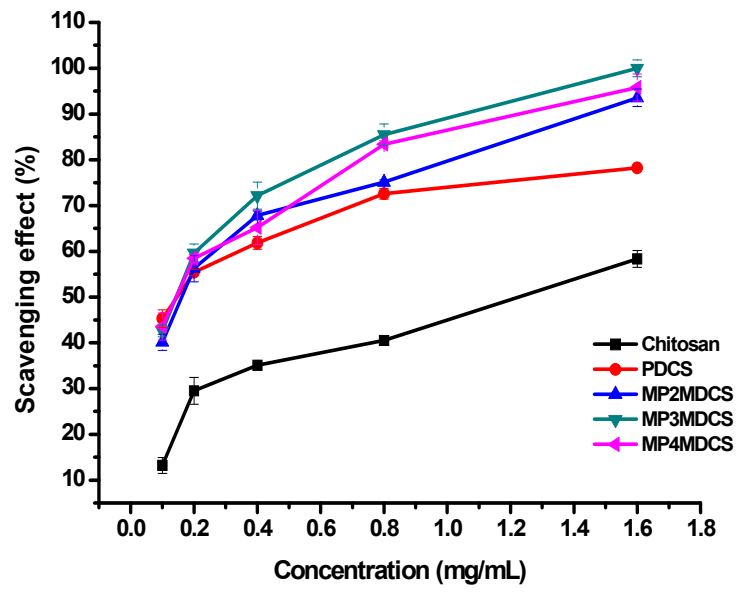

Figure 4. Hydroxyl radicals' scavenging ability of Chitosan, PDCS, MP2MDCS, MP3MDCS and MP4MDCS. 
The scavenging abilities of chitosan, PDCS, MP2MDCS, MP3MDCS, and MP4MDCS against DPPH radicals were shown in Figure 5. The results were similar to those of scavenging superoxide radicals and hydroxyl radicals too. Firstly, the sample had a positive correlation with the increasing concentration. Secondly, the scavenging indices were listed as followed: Chitosan 16.93\%, PDCS 62.60\%, MP2MDCS 94.80\%, MP3MDCS 97.80\%, and MP4MDCS 95.08\%. All double quaternary ammonium salts could improve the ability of scavenging DPPH radicals significantly.

Based on the results mentioned above, the scavenging ability of the products against superoxide radicals, hydroxyl radicals, and DPPH radicals were almost in order of MP3MDCS > MP4MDCS > MP2MDCS > PDCS > Chitosan at $1.6 \mathrm{mg} / \mathrm{mL}$, which could conclude that the antioxidant ability might associate with the density of the positive charge, as the positive charge could attract the single electron of free radicals to damage the free radical chain reaction. All double quaternized chitosan derivatives with higher density positive charges than chitosan and PDCS would attract more single electron of free radicals, which could improve the antioxidant ability. Furthermore, different $N$-pyridinium positions could have different influences on the antioxidant activity. The delocalization of pyridine was remarkable at the 2- and 4-position, which was enhanced if the nitrogen was protonated. So the distribution electronic cloud of MP2MDCS and MP4MDCS were more uniform than MP3MDCS in pyridine ring, which could explain MP3MDCS had a better antioxidant ability than MP2MDCS and MP4MDCS [30,36,37]. Based on the above results, it will be reasonable to presume that the density of positive charges and the different $N$-pyridinium position can influence the antioxidant property of chitosan derivatives. Further comprehensive investigation to ascertain the antioxidant mechanism and the structure-activity relationship would be studied in the future.

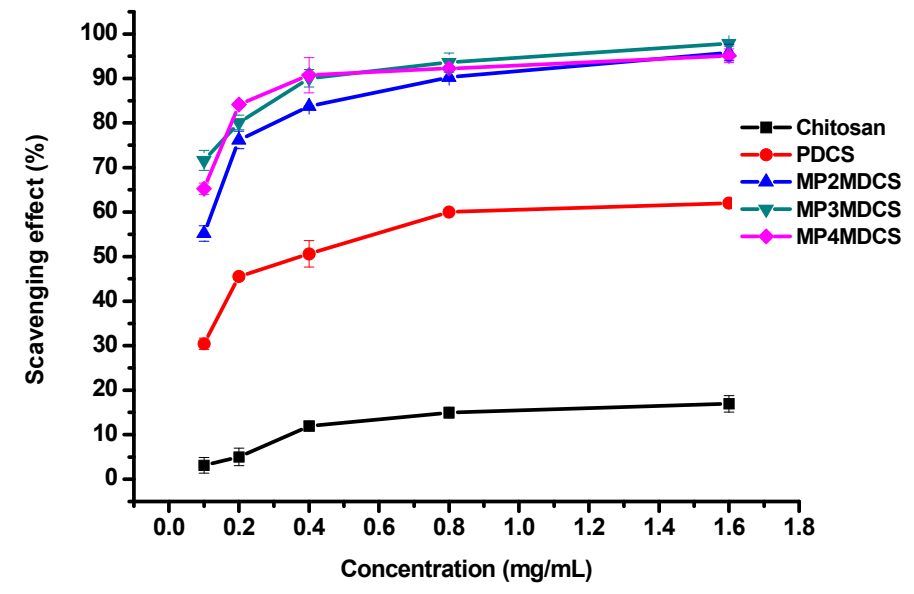

Figure 5. DPPH radicals scavenging ability of Chitosan, PDCS, MP2MDCS, MP3MDCS, and MP4MDCS.

\section{Materials and Methods}

\subsection{Materials}

Chitosan (MW $2.0 \times 10^{5}$, the degree of deacetylation 97\%) was purchased from Qingdao Baicheng Biochemical Corp. (Qingdao, China). In addition, 2-pyridinecarboxaldehyde, 3-pyridinecarboxaldehyde and 4-pyridinecarboxaldehyde were purchased from Aladdin Industrial Corp. (Shanghai, China) Sodium borohydride $\left(\mathrm{NaBH}_{4}\right), \mathrm{N}$-methyl-2-pyrrolidone (NMP), iodomethane $\left(\mathrm{CH}_{3} \mathrm{I}\right)$, sodium iodide $(\mathrm{NaI})$, and sodium hydroxide $(\mathrm{NaOH})$ were purchased from Sinopharm Chemical Reagent Co., Ltd. (Shanghai, China).

\subsection{Analytical Methods}

FT-IR spectrometers were recorded on a Jasco-4100 ranging from $4000 \mathrm{~cm}^{-1}$ to $400 \mathrm{~cm}^{-1}$ (Japan, provided by JASCO Co., Ltd., Shanghai, China) with KBr disks. ${ }^{1} \mathrm{H}$ NMR was recorded on a Bruker 
AVIII 500 spectrometer (Fällanden, Switzerland, provided by Bruker Biospin CN/Bruker (Beijing, China) Tech. and Serv. Co., Ltd., Beijing, China), using $\mathrm{D}_{2} \mathrm{O}$ as solvents with tetramethylsilane (TMS) as internal standard. Chemical shift values were given in $\delta(\mathrm{ppm})$. The elemental analyses $(\mathrm{C}, \mathrm{H}$, and N) were performed on a Vario EL III (Elementar, Langenselbold, Germany). The Degree of Substitution (DS) of chitosan derivatives were calculated based on the percentages of carbon and nitrogen, which is acquired by following Fonseca et al.'s method [38]. The UV-vis absorbance of the tested mixture were measured with a T6 New Century UV spectrometer (China, provided by P General Co., Ltd., Beijing, China). The results are processed by computer programs Excel (Microsoft, Redmond, WA, DC, USA) and Origin 8 (OriginLab, Northampton, MA, USA) and reported as mean \pm SD.

\subsection{Synthesis of Single Quaternized Chitosan (PDCS)}

Single quaternized chitosan PDCS was prepared according to an earlier method [34]. In brief, $1.61 \mathrm{~g}$ chitosan was dissolved into $50 \mathrm{~mL} 1 \%$ acetic acid aqua and $50 \mathrm{~mL}$ ethanol in flask at $25^{\circ} \mathrm{C}$, and $3.05 \mathrm{~mL}$ benzaldehyde were added with stirring at $25^{\circ} \mathrm{C}$. After $2 \mathrm{~h}, 1.8 \mathrm{~g} \mathrm{NaBH}$ was added and the reaction was carried out for $2 \mathrm{~h}$. The solution was precipitated into acetone and the precipitants were filtered. Then, the $\mathrm{N}$-substituted chitosan derivative was obtained after drying at $60^{\circ} \mathrm{C}$ for $24 \mathrm{~h}$. Then, $0.5 \mathrm{~g} \mathrm{~N}$-substituted chitosan was dispersed into $30 \mathrm{~mL} \mathrm{~N}$-methyl-2-pyrrolidone (NMP) for $12 \mathrm{~h}$ at $25^{\circ} \mathrm{C}$. To this mixture, $0.1 \mathrm{~mL} \mathrm{NaOH}(1 \mathrm{M}), 0.75 \mathrm{~g} \mathrm{NaI}$, and $2 \mathrm{~mL} \mathrm{CH}_{3} \mathrm{I}$ were added, and the reaction was refluxed gently with stirring at $60^{\circ} \mathrm{C}$ for $4 \mathrm{~h}$. The solution was precipitated by excess acetone and the precipitations were filtered. The single quaternized chitosan derivative was obtained by drying at $60{ }^{\circ} \mathrm{C}$ for $24 \mathrm{~h}$ (Scheme 1), yield: $90.30 \%$; DS: $78.32 \%$ (Table 1).

Table 1. The elemental analyses, yields, and the degrees of substitution of chitosan derivatives.

\begin{tabular}{|c|c|c|c|c|c|c|c|}
\hline \multirow{2}{*}{ Compounds } & \multirow{2}{*}{ Yields (\%) } & \multicolumn{4}{|c|}{ Elemental Analyses (\%) } & \multirow{2}{*}{$\begin{array}{c}\text { Degrees of } \\
\text { Substitution (\%) }\end{array}$} & \multirow{2}{*}{$\begin{array}{c}\text { Deacetylation } \\
(\%)\end{array}$} \\
\hline & & $\mathrm{C}$ & $\mathbf{N}$ & $\mathbf{H}$ & $\mathrm{C} / \mathrm{N}$ & & \\
\hline Chitosan & & 41.450 & 7.980 & 6.201 & 5.19 & & \\
\hline PDCS & 90.30 & 34.553 & 3.072 & 5.465 & 11.24 & 78.9 & 97 \\
\hline MP2MDCS & 93.54 & 35.717 & 5.611 & 5.618 & 6.366 & 88.0 & \\
\hline MP3MDCS & 94.62 & 31.645 & 5.026 & 5.373 & 6.296 & 76.5 & \\
\hline MP4MDCS & 93.80 & 30.252 & 4.801 & 5.367 & 6.300 & 77.0 & \\
\hline
\end{tabular}

\subsection{Synthesis of Double Quaternized Chitosan (MP2MDCS, MP3MDCS, and MP4MDCS)}

Double quaternized chitosan MP2MDCS, MP3MDCS, and MP4MDCS were synthesized as follows: $1.61 \mathrm{~g}$ chitosan was dissolved into $50 \mathrm{~mL} 1 \%$ acetic acid aqua and $50 \mathrm{~mL}$ ethanol in flask at $25^{\circ} \mathrm{C}$, and $30 \mathrm{mmol}$ 2-pyridinecarboxaldehyde $(2.85 \mathrm{~mL}), 3$-pyridinecarboxaldehyde $(2.82 \mathrm{~mL})$, and 4-pyridinecarboxaldehyde $(2.86 \mathrm{~mL})$ were added, respectively, with stirring at $25^{\circ} \mathrm{C}$. After $2 \mathrm{~h}, 1.8 \mathrm{~g}$ $\mathrm{NaBH}_{4}$ was added and the reaction was carried out continuously for $2 \mathrm{~h}$. The solution was precipitated into excess acetone and the precipitant were filtrated. Then, the $N$-methylpyridine chitosan derivatives were obtained after drying at $60^{\circ} \mathrm{C}$ for $6 \mathrm{~h}$. In addition, $0.5 \mathrm{~g}$ above synthesized $\mathrm{N}$-methylpyridine chitosan was dispersed into $30 \mathrm{~mL} \mathrm{NMP} \mathrm{for} 12 \mathrm{~h}$ at $25^{\circ} \mathrm{C}$. The reaction was carried out at $60^{\circ} \mathrm{C}$ for $4 \mathrm{~h}$ with reflux stirring after $0.2 \mathrm{~mL} \mathrm{NaOH}$ solution $(1 \mathrm{M}), 1.5 \mathrm{~g} \mathrm{NaI}$ and $4 \mathrm{~mL} \mathrm{CH}_{3} \mathrm{I}$ were added. The solution was precipitated by excess acetone and the precipitations were filtered. The double quaternized chitosan derivatives were obtained by drying at $60^{\circ} \mathrm{C}$ for $24 \mathrm{~h}$ (Scheme 1), MP2MDCS yield: $93.54 \%$; DS: 88.0\%; MP3MDCS yield: 94.62\%; DS: 76.5\%; MP4MDCS yield: $93.80 \%$; DS: 77.0\% (Table 1).

\subsection{Hydroxyl Radicals' Scavenging Activity Assay}

The reaction of Fe-EDTA complex with $\mathrm{H}_{2} \mathrm{O}_{2}$ in phosphate buffer can generate $\cdot \mathrm{OH}$, which is harmful to the body through reacting with biological molecule such as amino acid or DNA. The hydroxyl radical scavenging activity was measured according to Guo and Liu $[5,34]$. The reaction mixture, total 
volume $4.5 \mathrm{~mL}$, containing the samples of chitosan or chitosan derivatives $(10 \mathrm{mg} / \mathrm{mL}, 0.045,0.09$, $0.18,0.36$, and $0.72 \mathrm{~mL})$, were incubated with EDTA-Fe ${ }^{2+}(220 \mu \mathrm{M})$, potassium phosphate buffer (150 mM, pH 7.4), safranine $\mathrm{T}(0.23 \mu \mathrm{M})$ and $\mathrm{H}_{2} \mathrm{O}_{2}(60 \mu \mathrm{M})$ for $30 \mathrm{~min}$ at $37^{\circ} \mathrm{C}$. The absorbance of the mixture was measured at $520 \mathrm{~nm}$. Three replicates for each sample concentration were tested. The $\cdot \mathrm{OH}$ bleached the safranine $\mathrm{T}$, so decreased absorbance of the reaction mixture indicated decreased . OH scavenging ability, and the capability of scavenging $\cdot \mathrm{OH}$ was calculated using the follow equation: Scavenging effect $(\%)=\left(A_{\text {sample 520nm }}-A_{\text {blank 520nm }}\right) /\left(A_{\text {control 520nm }}-A_{\text {blank } 520 \mathrm{~nm}}\right) \times 100$,

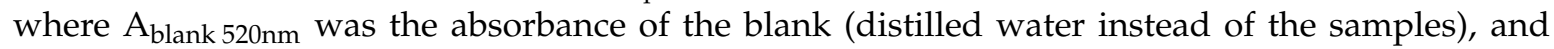
$\mathrm{A}_{\text {control 520nm }}$ was the absorbance of the control (distilled water instead of $\mathrm{H}_{2} \mathrm{O}_{2}$ ).

\subsection{Superoxide Radicals' Scavenging Ability Assay}

The superoxide radical ability was assessed by the method of Nishikimi et al. [39]. Superoxide radicals can generate single oxygen or hydroxyl radicals which could cause the peroxidation of lipids [40], which would be deleterious to the body. Involving testing samples of chitosan or chitosan derivatives $(5 \mathrm{mg} / \mathrm{mL}, 0.06,0.12,0.24,0.48$, and $0.96 \mathrm{~mL}), 30 \mu \mathrm{M}$ phenazine methosulfate (PMS), $338 \mu \mathrm{M}$ nicotinamide adenine dinucleotide reduced (NADH), and $72 \mu \mathrm{M}$ nitro blue tetrazolium (NBT) in Tris- $\mathrm{HCl}$ buffer $(16 \mathrm{mM}, \mathrm{pH} 8.0)$, the reaction mixture was incubated at $25^{\circ} \mathrm{C}$ for $5 \mathrm{~min}$. The absorbance was read at $560 \mathrm{~nm}$ against a blank. Three replicates for each sample concentration were tested and the capability of scavenging superoxide radical was calculated using the following equation: Scavenging effect $(\%)=\left[1-\left(A_{\text {sample } 560 \mathrm{~nm}}-A_{\text {control 560nm }}\right) / A_{\text {blank 560nm }}\right] \times 100$, where $A_{\text {control } 560 \mathrm{~nm}}$ is the absorbance of the control (distilled water instead of NADH for each concentration) and $A_{\text {blank } 560 \mathrm{~nm}}$ is the absorbance of the blank (distilled water instead of the samples).

\subsection{DPPH Radicals' Scavenging Ability Assay}

According to HU [35], the DPPH radical scavenging ability of chitosan, PDCS, MP2PDCS, MP3MDCS, and MP4MDCS were measured as followed: testing samples $(10 \mathrm{mg} / \mathrm{mL}, 0.03,0.06$, $0.12,0.24$ and $0.48 \mathrm{~mL})$ and $2 \mathrm{~mL}$ ethanol solution of DPPH $(180 \mu \mathrm{mol} / \mathrm{L})$ was incubated for $30 \mathrm{~min}$ at $25{ }^{\circ} \mathrm{C}$. Then, the absorbance of the remained DPPH radical was measured at $517 \mathrm{~nm}$ against a blank. Three replicates for each sample concentration were tested and the scavenging effect was obtained according to the following equation: Scavenging effect $(\%)=\left[1-\left(\mathrm{A}_{\text {sample }} 517 \mathrm{~nm}-\right.\right.$ $A_{\text {control 517nm }}$ ) $\left./ A_{\text {blank 517nm }}\right] \times 100$, where $A_{\text {control 517nm }}$ is the absorbance of the control (ethanol instead of DPPH for each concentration) and $A_{\text {blank } 517 \mathrm{~nm}}$ is the absorbance of the blank (distilled water instead of the samples).

\section{Conclusions}

Via $N$-pyridylmethyl chitosan, a series of derivatives of chitosan with single or double quaternary ammonium salts were synthesized successfully. In addition, antioxidant activities of chitosan and quaternized chitosan derivatives against hydroxyl radicals, DPPH radicals, and superoxide radicals were tested in vitro. It was found that all quaternized chitosan derivatives had good water solubility and stronger antioxidant ability compared with chitosan, especially double quaternized chitosan derivatives that might be further developed into more effective antioxidant biomaterials. These data demonstrated that the higher positive charge density of quaternized chitosan derivatives might contribute to antioxidant activities. Furthermore, MP3MDCS was more effective than MP2MDCS and MP4MDCS in all assays especially at $1.6 \mathrm{mg} / \mathrm{mL}$. It was reasonable to presume that the $N$-pyridinium position of double quaternized chitosan derivatives could influence the antioxidant property. Besides, it was reported that pyridinium derivatives were showed to be non-toxic for genen delivery in vitro among the quaternary ammonium chitosans [30], so our double quaternized chitosan derivatives might have lower toxicity, which needs to be studied further. Finally the mechanism of the antioxidant activity and the structure-activity relationship need to be further investigated in the future. 
Acknowledgments: We thank the National Natural Science Foundation of China (41576156), the Shandong Province Science and Technology Development Plan (2015GSF121045), the Yantai Science and Technology Development Plan (2015ZH078), and the Public Science and Technology Research Funds Projects of Oceans (No. 201505022-3) for financial support of this work.

Author Contributions: Lijie Wei participated in designing the experiments, wrote the paper, and was the chief experimenter. Fang Dong, Wenqiang Tan and Fang Luan also performed the experiments and participated in analyzing the data. Qing Li participated in analyzing the data and was responsible for the language modification. Zhanyong Guo was the chief designer and the instructor of the experiment, and analyzed the experimental data. All authors read and approved the final manuscript.

Conflicts of Interest: The authors declare no conflict of interest

\section{Abbreviations}

The following abbreviation are used in this manuscript:

$\begin{array}{ll}\text { PDCS } & N \text {-phenmethyl- } N, N \text {-dimethyl chitosan } \\ \text { MP3MDCS } & N \text {-(1-methylpyridin-3-ylmethyl)- } N, N \text {-dimethyl chitosan } \\ \text { MP4MDCS } & N \text {-(1-methylpyridin-4-ylmethyl)- } N, N \text {-dimethyl chitosan } \\ \text { MP2MDCS } & N \text {-(1-methylpyridin-2-ylmethyl)- } N, N \text {-dimethyl chitosan } \\ \text { DPPH } & 1,1 \text {-Diphenyl-2-picrylhydrazyl } \\ \text { EDTA } & \text { Ethylenediaminetetraacetic acid }\end{array}$

\section{References}

1. Wojtunik-Kulesza, K.A.; Oniszczuk, A.; Oniszczuk, T.; Waksmundzka-Hajnos, M. The influence of common free radicals and antioxidants on development of Alzheimer's Disease. Biomed. Pharmacother. 2016, 78, 39-49. [CrossRef] [PubMed]

2. Valko, M.; Leibfritz, D.; Moncol, J.; Cronin, M.T.; Mazur, M.; Telser, J. Free radicals and antioxidants in normal physiological functions and human disease. Int. J. Biochem. Cell B 2007, 39, 44-84. [CrossRef] [PubMed]

3. De Freitas, B.M.; Stadnik, J.M. Ulvan-induced resistance in Arabidopsis thaliana against Alternaria brassicicola requires reactive oxygen species derived from NADPH oxidase. Physiol. Mol. Plant Pathol. 2015, 90,49-56. [CrossRef]

4. Wei, D.; Cheng, W.; Wei, Y.; Zhang, L. Phosphorylated modification and in vitro antioxidant activity of Radix Hedysari polysaccharide. Glycoconj. J. 2012, 29, 167-172. [CrossRef] [PubMed]

5. Liu, J.; Sun, H.; Dong, F.; Xue, Q.; Wang, G.; Qin, S.; Guo, Z. The influence of the cation of quaternized chitosans on antioxidant activity. Carbohydr. Polym. 2009, 78, 439-443. [CrossRef]

6. Winata, A.; Lorenz, K. Aatioxidant potential of 5-n-pentadecylresorcinol. J. Food Process. Presrv. 1996, 20, 417-429. [CrossRef]

7. Yang, S.; Guo, Z.; Miao, F.; Xue, Q.; Qin, S. The hydroxyl radical scavenging activity of chitosan, hyaluronan, starch and their O-carboxymethylated derivatives. Carbohydr. Polym. 2010, 82, 1043-1045. [CrossRef]

8. Castagnino, E.; Ottaviani, M.F.; Cangiotti, M.; Morelli, M.; Casettari, L.; Muzzarelli, R.A. Radical scavenging activity of 5-methylpyrrolidinone chitosan and dibutyryl chitin. Carbohydr. Polym. 2008, 74, 640-647. [CrossRef]

9. Rabea, E.I.; Badawy, M.E.-T.; Stevens, C.V.; Smagghe, G.; Steurbaut, W. Chitosan as antimicrobial agent: Applications and mode of action. Biomacromolecules 2003, 4, 1457-1465. [CrossRef] [PubMed]

10. El Ghaouth, A.; Arul, J.; Wilson, C.; Benhamou, N. Biochemical and cytochemical aspects of the interactions of chitosan and Botrytis cinerea in bell pepper fruit. Postharvest Biol. Technol. 1997, 12, 183-194. [CrossRef]

11. Sudarshan, N.; Hoover, D.; Knorr, D. Antibacterial action of chitosan. Food Biotechnol. 1992, 6, $257-272$. [CrossRef]

12. Ngo, D.H.; Kim, S.K. Antioxidant effects of chitin, chitosan, and their derivatives. Adv. Food Nutr. Res. 2014, 73, 15-31. [PubMed]

13. Chien, R.C.; Yen, M.T.; Mau, J.L. Antimicrobial and antitumor activities of chitosan from shiitake stipes, compared to commercial chitosan from crab shells. Carbohydr. Polym. 2016, 138, 259-264. [CrossRef] [PubMed]

14. Lim, S.H.; Hudson, S.M. Synthesis and antimicrobial activity of a water-soluble chitosan derivative with a fiber-reactive group. Carbohydr. Res. 2004, 339, 313-319. [CrossRef] [PubMed] 
15. Li, Q.; Tan, W.; Zhang, C.; Gu, G.; Guo, Z. Novel triazolyl-functionalized chitosan derivatives with different chain lengths of aliphatic alcohol substituent: Design, synthesis, and antifungal activity. Carbohydr. Res. 2015, 418, 44-49. [CrossRef] [PubMed]

16. Liu, X.; Guan, Y.; Yang, D.; Li, Z.; Yao, K. Antibacterial action of chitosan and carboxymethylated chitosan. J. Appl. Polym. Sci. 2001, 79, 1324-1335.

17. Liu, J.; Wen, X.; Lu, J.; Kan, J.; Jin, C. Free radical mediated grafting of chitosan with caffeic and ferulic acids: Structures and antioxidant activity. Int. J. Biol. Macromol. 2014, 65, 97-106. [CrossRef] [PubMed]

18. Guo, Z.; Xing, R.; Liu, S.; Zhong, Z.; Li, P. Synthesis and hydroxyl radicals scavenging activity of quaternized carboxymethyl chitosan. Carbohydr. Polym. 2008, 73, 173-177. [CrossRef]

19. Zhong, Z.; Chen, R.; Xing, R.; Chen, X.; Liu, S.; Guo, Z.; Ji, X.; Wang, L.; Li, P. Synthesis and antifungal properties of sulfanilamide derivatives of chitosan. Carbohydr. Res. 2007, 342, 2390-2395. [CrossRef] [PubMed]

20. Shanmugam, A.; Kathiresan, K.; Nayak, L. Preparation, characterization and antibacterial activity of chitosan and phosphorylated chitosan from cuttlebone of Sepia kobiensis (Hoyle, 1885). Biotechnol. Rep. 2016, 9 , 25-30. [CrossRef]

21. Jayakumar, R.; Nagahama, H.; Furuike, T.; Tamura, H. Synthesis of phosphorylated chitosan by novel method and its characterization. Int. J. Biol. Macromol. 2008, 42, 335-339. [CrossRef] [PubMed]

22. Tan, W.; Li, Q.; Li, W.; Dong, F.; Guo, Z. Synthesis and antioxidant property of novel 1,2,3-triazole-linked starch derivatives via "click chemistry". Int. J. Biol. Macromol. 2016, 82, 404-410. [CrossRef] [PubMed]

23. Fujimoto, K.; Morisaki, D.; Yoshida, M.; Namba, T.; Hye-Sook, K.; Wataya, Y.; Kourai, H.; Kakuta, H.; Sasaki, K. Antimalarial effect of bis-pyridinium salts, $N, N^{\prime}$-hexamethylenebis(4-carbamoyl-1-alkylpyridinium bromide). Bioorg. Med. Chem. Lett. 2006, 16, 2758-2760. [CrossRef] [PubMed]

24. Sajomsang, W.; Ruktanonchai, U.R.; Gonil, P.; Warin, C. Quaternization of N-(3-pyridylmethyl) chitosan derivatives: Effects of the degree of quaternization, molecular weight and ratio of $N$-methylpyridinium and $N, N, N$-trimethyl ammonium moieties on bactericidal activity. Carbohydr. Polym. 2010, 82, 1143-1152. [CrossRef]

25. Badawy, M.E.I. Chemical modification of chitosan: Synthesis and biological activity of new heterocyclic chitosan derivatives. Polym. Int. 2008, 57, 254-261. [CrossRef]

26. Jia, R.; Duan, Y.; Fang, Q.; Wang, X.; Huang, J. Pyridine-grafted chitosan derivative as an antifungal agent. Food Chem. 2016, 196, 381-387. [CrossRef] [PubMed]

27. Sajomsang, W.; Tantayanon, S.; Tangpasuthadol, V.; Daly, W.H. Synthesis of methylated chitosan containing aromatic moieties: Chemoselectivity and effect on molecular weight. Carbohydr. Polym. 2008, 72, 740-750. [CrossRef]

28. Bao, S.; Nomura, T. Silver-selective sensor using an electrode-separated piezoelectric quartz crystal modified with a chitosan derivative. Anal. Sci. 2002, 18, 881-885. [CrossRef] [PubMed]

29. Sajomsang, W.; Rungsardthong Ruktanonchai, U.; Gonil, P.; Nuchuchua, O. Mucoadhesive property and biocompatibility of methylated $N$-aryl chitosan derivatives. Carbohydr. Polym. 2009, 78, 945-952. [CrossRef]

30. Sajomsang, W.; Gonil, P.; Ruktanonchai, U.R.; Petchsangsai, M.; Opanasopit, P.; Puttipipatkhachorn, S. Effect of $N$-pyridinium positions of quaternized chitosan on transfection efficiency in gene delivery system. Carbohydr. Polym. 2014, 104, 17-22. [CrossRef] [PubMed]

31. Rodrigues, C.A.; Laranjeira, M.C.; de Fávere, V.T.; Stadler, E. Interaction of Cu(II) on N-(2-pyridylmethyl) and N-(4-pyridylmethyl) chitosan. Polymer 1998, 39, 5121-5126. [CrossRef]

32. Sajomsang, W.; Ruktanonchai, U.; Gonil, P.; Mayen, V.; Opanasopit, P. Methylated N-aryl chitosan derivative/DNA complex nanoparticles for gene delivery: Synthesis and structure-activity relationships. Carbohydr. Polym. 2009, 78, 743-752. [CrossRef]

33. Guo, Z.; Xing, R.; Liu, S.; Yu, H.; Wang, P.; Li, C.; Li, P. The synthesis and antioxidant activity of the Schiff bases of chitosan and carboxymethyl chitosan. Bioorg. Med. Chem. Lett. 2005, 15, 4600-4603. [CrossRef] [PubMed]

34. Guo, Z.; Liu, H.; Chen, X.; Ji, X.; Li, P. Hydroxyl radicals scavenging activity of $N$-substituted chitosan and quaternized chitosan. Bioorg. Med. Chem. Lett. 2006, 16, 6348-6350. [CrossRef] [PubMed]

35. Hu, Y.; Zhang, J.; Yu, C.; Li, Q.; Dong, F.; Wang, G.; Guo, Z. Synthesis, characterization, and antioxidant properties of novel inulin derivatives with amino-pyridine group. Int. J. Biol. Macromol. 2014, 70, 44-49. [CrossRef] [PubMed] 
36. Li, Q.; Zhang, C.; Tan, W.; Gu, G.; Guo, Z. Novel Amino-Pyridine Functionalized Chitosan Quaternary Ammonium Derivatives: Design, Synthesis, and Antioxidant Activity. Molecules 2017, 22, 156-165. [CrossRef] [PubMed]

37. Carey, F.A.; Sundberg, R.J. Advanced Organic Chemistry, Part A: Structrue and Mechanisms, 5th ed.; Springer: Beijing, China, 2009; pp. 793-794.

38. Dos Santos, Z.; Caroni, A.; Pereira, M.; da Silva, D.; Fonseca, J. Determination of deacetylation degree of chitosan: A comparison between conductometric titration and CHN elemental analysis. Carbohydr. Res. 2009, 344, 2591-2595. [CrossRef] [PubMed]

39. Nishikimi, M.; Rao, N.A.; Yagi, K. The occurrence of superoxide anion in the reaction of reduced phenazine methosulfate and molecular oxygen. Biochem. Biophys. Res. 1972, 46, 849-854. [CrossRef]

40. Xing, R.; Liu, S.; Guo, Z.; Yu, H.; Li, C.; Ji, X.; Feng, J.; Li, P. The antioxidant activity of glucosamine hydrochloride in vitro. Bioorg. Med. Chem. 2006, 14, 1706-1709. [CrossRef] [PubMed]

Sample Availability: Samples of the compounds PDCS, MP2MDCS, MP3MDCS, and MP4MDCS are available from the authors.

(C) 2017 by the authors. Licensee MDPI, Basel, Switzerland. This article is an open access article distributed under the terms and conditions of the Creative Commons Attribution (CC BY) license (http:/ / creativecommons.org/licenses/by/4.0/). 